\title{
Interdependence of food and space limitation of a benthic suspension feeder: consequences for self-thinning relationships
}

\author{
Marcel Fréchette, Alec E. Aitken*, Lucie Pagé \\ Institut Maurice-Lamontagne, Ministère des Pêches et des Océans, C.P. 1000, Mont-Joli, Québec, Canada G5H 3Z4
}

\begin{abstract}
We test the idea that competition for space and food in benthic suspension feeders is interdependent. Experimental evidence in support of this concept has been presented only for bryozoans. We present an experimental rejection of the hypothesis of the independence of food and space as factors limiting individual growth in small groups of blue mussel Mytilus edulis (L.). Mussels were grown in the laboratory, using natural seawater. In the present experiment, physical interference (crowding) and exploitative competition for food did co-occur. Growth of mussels changed from positive to negative along an assumed food gradient in series of the chambers employed in this experiment. In addition, growth was severely impeded by interference in small individuals, but not in large individuals: competition was asymmetrical with respect to size. We present a model of this interaction based on a biomechanical analysis of the effect of reduction of shell gape in neighbouring mussels interacting together. The model predicts that the effect of interference on individual growth is sizedependent and can be determined in terms of the shell-length/body-mass relationship. In the context of predicting self-thinning slopes in bivalves, our data strongly suggest that simultaneous occurrence of physical interference and exploitative competition results in a steepening of the expected slope $(\beta)$ of space-limited self-thinning relationships, when log biomass $(B)$ is expressed as a function of log density $(N)$ in the equation $\log B=\log k+\beta \log N$.
\end{abstract}

\section{INTRODUCTION}

Early demonstrations of density-dependent growth and survival in sessile suspension-feeding invertebrates have implicated space as the limiting factor (see references in Buss 1979). It was later reported that overgrowth interactions in bryozoans were driven by competition for food at the margin of the colonies (Buss 1979), which has led to the concept of interdependence of competition for space and food in benthic suspension feeders. Although it is true that sessile animals cannot separate spatially or temporally their feeding requirements and their need to occupy a substratum, this is by no means a reason to equate space with food (Fréchette \& Lefaivre 1990). Indeed, the nature of the limiting factor - crowding or food - may have different

\footnotetext{
- Present address: Department of Geography, Division of Social Sciences, Scarborough College, University of Toronto, 1265 Military Trail, Scarborough, Ontario, Canada M1C 1A4
}

consequences for (1) the ecology of the competing organisms themselves (population dynamics: Schoener 1973, Beddington 1975, Jensen 1987), (2) the relationship between abundance and body mass as revealed by self-thinning relationships (Norberg 1988, Fréchette \& Lefaivre 1990), (3) management (shellfish culture: Fréchette \& Lefaivre 1990), or (4) community structure (Maclsaac \& Gilbert 1991). The concept of interdependence of limiting factors, consequently, has to be evaluated experimentally for taxa other than bryozoans.

Previous research relating to the concept of interdependence of food and space limitation has relied on (1) study of expected population dynamics of predator and prey (Schoener 1973, Beddington 1975, Jensen 1987). (2) manipulation of population density and spatial organization of individuals (Peterson \& Andre 1980, Peterson 1982, Anholt 1990, Myers 1990) and (3) mathematical analysis of self-thinning relationships (Norberg 1988, Fréchette \& Lefaivre 1990). 
Self-thinning relationships represent an upper limit above which combinations of population density $(N)$ and biomass $(B)$ cannot occur because of intraspecific competition (Yoda et al. 1963, Weller 1990). Selfthinning relationships can be expressed as $B=k N^{\beta}$, with $\beta<0$. It is customary to represent self-thinning relationships using logarithmically transformed data, with $\log B=\log k+\beta \log N$, where $\beta$ is the slope, and $k$ is the intercept of the relationship. Predicted values of $\beta$ may differ, depending on whether food or space limitation is assumed (Norberg 1988, Fréchette \& Lefaivre 1990). In food-limited populations, $k$ is also expected to vary, according to the metabolic efficiency of the animals and to site quality (Fréchette \& Lefaivre 1990). The self-thinning methodology for identifying limiting factors assumes that food and space limitations arise from mechanistically independent processes, or at least that they do not co-occur. The following experiment was designed to test this assumption.

\section{MATERIAL AND METHODS}

The experiment was conducted in a small laboratory near the shore at Pointe-aux-Cenelles, Québec $\left(48^{\circ} 38^{\prime} \mathrm{N}, 68^{\circ} 10^{\prime} \mathrm{W}\right)$, along the St. Lawrence Estuary. It lasted from 19 May to 19 July 1989. Groups of individuals of blue mussel Mytilus edulis L. were grown in 4 sets of twelve $1 \mathrm{l}$ flow-through chambers arranged in series. The mussels were fed natural particles, as seawater was pumped directly from the Estuary to a head tank and then distributed to the growth chambers by gravity. Flow rates in the chambers were monitored daily, and adjusted when necessary so as to equal $0.600 \pm 0.040 \mathrm{l}$ $\mathrm{min}^{-1}$ for each series. Within each chamber, the mussels were kept in cages that occupied as much as possible of the chamber volume, except for the lowermost $2 \mathrm{~cm}$ near the bottom of the cage. This allowed room for biodeposits and other sedimented materials to accumulate away from the mussels. The chambers were cleaned weekly to remove sedimented materials, or whenever wind events resulted in pumping sufficiently high amounts of resuspended sediments from the Estuary into the chambers, to necessitate more frequent cleaning.

A diagram of the experimental setup is given in Fig. 1 Two initial sizes of mussels were used. In 2 series of chambers, 10 mussels of each of the small $(2.0 \pm 0.1 \mathrm{~cm}$ shell length) and large $(4.5 \pm 0.2 \mathrm{~cm}$ shell length) size-classes were placed in the evennumbered chambers (mixed mussels, Series B and $C_{i}$ Fig. 1). In each of the other 2 series, the 12 chambers were occupied alternatively by small mussels (10 individuals) and large mussels (10 individuals), beginning with small mussels in one series, and with large mussels in the other (separated mussels, Series A and D; Fig. 1). It has been demonstrated (Okamura 1986) that mussels living in small groups ( 6 to 9 individuals) grow at the same rate as individual mussels, but faster than mussels living in large groups (21 to 28 individuals). We chose initial densities to be either 10 individuals per chamber (no interference) or 20 individuals per chamber (interference present).

In such a setup, individual growth is expected to decrease downstream in each of the series of chambers as seston becomes progressively depleted by the mussels (Wildish \& Kristmanson 1985). For each size class, the cumulative density of mussels in the evennumbered chambers is the same. The upstreamdownstream gradient in body mass ( $m$; soft parts only) should be the same in all series of chambers, therefore, with only food limitation affecting the results. Within each size class, we used the comparison of mean final body mass of mixed mussels and separated mussels at even positions along the series of chambers as a sufficient criterion for the resolution of an added component (i.e. physical interference via crowding) to the food-related gradient. For example, the size of small mussels in the second box of Series A and B could be compared, and the same could be done for large mussels in the second box of Series C and D.

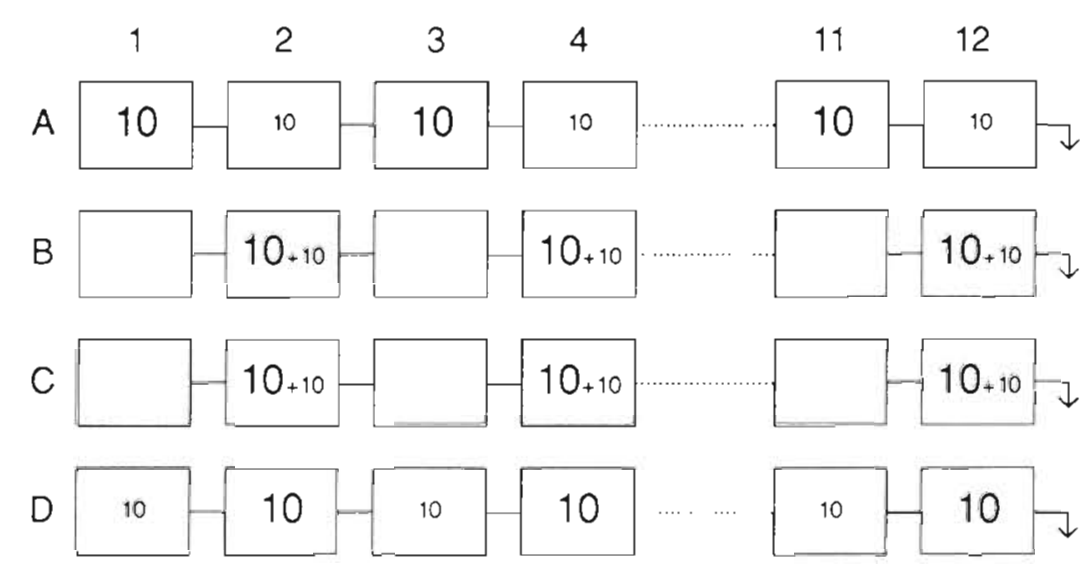

Fig. 1 Experimental setup. Arrows indicate the direction of water flow. Small and large numbers indicate numbers of small and large mussels in each chamber 
In this experiment, we did not attempt to manipulate food concentration directly, but rather relied on the mussels themselves to generate a food concentration gradient. Based on initial body mass of mussels and the relationship between pumping rate and body mass (Thompson 1984), total predicted pumping rate of 10 large and 10 small mussels was equal to about half of the flow rate through the chambers. Assuming that pumping rate does not vary with food concentration, this would imply that only about $1.5 \%$ of the incoming food left the 12 th chamber. We did not attempt to measure food concentration along the series of chambers, since removal of water from the system would have changed the effective flow rate, and thus the apparent removal rate of food by mussels. In addition, considering the total volume of 12 chambers and the flow rate of water, about 20 min would be required, on average, for a parcel of water entering the first chamber to exit the system. The highly heterogeneous character of phytoplankton biomass is likely to have generated a highly variable timeseries of food concentration in the water entering the system (see, for example, Fig. 3A in Fréchette et al. 1989). Given the large delay between the first and the distal chambers, any pattern in food concentration attributable to mussels would probably have been blurred by the combination of variations in input concentration and delays between chambers. Individual growth response of separated mussels and food concentration patterns in the chambers are presently being investigated using numerical modelling techniques (Lefaivre et al. unpubl.).

Initial ash-free dry body mass was computed for each mussel from its shell length (l) and the shelllength/body-mass relationship of the mussels, as determined on individuals from the same mussel population $\left(\log m=-1.99+2.60 \log l_{i} \mathrm{r}^{2}=0.94, \mathrm{n}=88\right.$, $\mathrm{p}<0.01$ ). Mean ( $\pm 1 \mathrm{SD}$ ) initial body mass was $0.063 \mathrm{~g}$ $( \pm 0.005 \mathrm{~g}, \mathrm{n}=240$ ) and $0.522 \mathrm{~g}( \pm 0.037 \mathrm{~g}, \mathrm{n}=240$ ) for small and large mussels, respectively. At the end of the experiment, mussels were frozen at $-18^{\circ} \mathrm{C}$. Dry body mass was measured after thawing, removing the byssus and drying at $70^{\circ} \mathrm{C}$ for $72 \mathrm{~h}$.

To analyse the results, mean mass of mixed mussels was plotted as a function of mean mass of separate mussels for each size group. In such a plot, significant interference would result in slopes smaller than 1 . The slopes for small and large mussels were tested separately using Model II regressions (Clarke 1980). The different series of mussels were matched by toss of a coin.

\section{RESULTS}

Survivorship was high in large mussels, but lower in small mussels. Only 3 of the 120 large mussels died. Among the small mussels, 13 and 21 individuals of the
60 employed in each of the mixed and separated treatments died.

In Fig. 2, data points follow from right to left the upstream-downstream arrangement of the chambers. There was some loss of soft-part body mass of large mussels in all except the first chamber, and of small mussels in the 2 most distal chambers. Visual observations of the mussels indicated that the experiment was terminated before the mussels had spawned. Body mass loss appears to have resulted from metabolic constraints on body size, energy intake being smaller than expenditure. Body mass loss is an important lifehistory response to food shortage in many organisms with indeterminate growth. In molluscs, unlike urchins, shells do not decrease in size (Sebens 1987. Levitan 1989).

The plot of mean final mass of large mixed mussels against mean final mass of large separated mussels shows that there was no significant effect of mixing on large mussel growth, since the slope of the relationship was not significantly different from 1: small mussels did not impede the growth of large mussels (Fig. 2, solid symbols). A different pattern emerges, however, when mean final body mass of small mixed mussels is plotted against mean final body mass of small sepa-

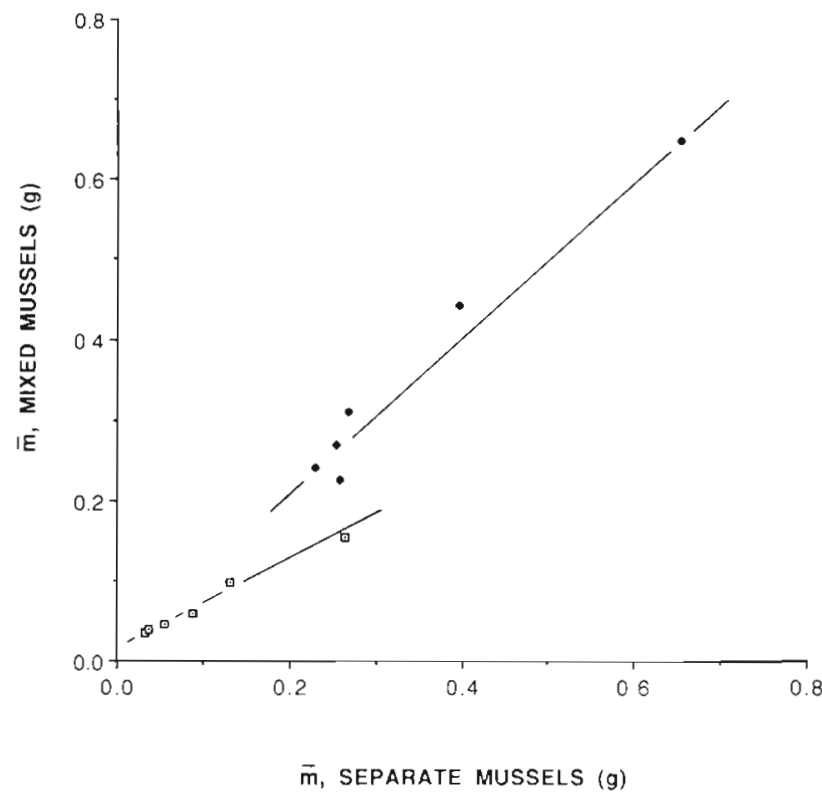

Fig. 2. Plot of mean body mass of mixed mussels (ordinate) and separated mussels (abscissa). The regression equation for the large mussels (filled symbols) is $\bar{m}_{\text {mixed }}=0.98 \bar{m}_{\text {scp. }}+0.02$; $\left.r^{2}=0.97, n=6, p<0.01\right)$. The slope of the relationship is not significantly different from 1 ( $T=0.02, \mathrm{df}=5, \mathrm{p}>0.05)$. The regression equation for the small mussels (open symbols) is $\left.\bar{m}_{\text {nuxed }}=0.52 \bar{m}_{\text {sep }}+0.02 ; r^{2}=0.99, \mathrm{n}=6, \mathrm{p}<0.01\right)$. The slope of the relationship is significantly smaller than $1(T=5.35$, $\mathrm{df}=5, \mathrm{p}<0.01$ ). For each size class, points follow from right to left the upstream-downstream arrangement of chambers 
rated mussels, which reflects a negative effect of the presence of large mussels on the growth of small mussels (Fig. 2, open symbols). The absolute intensity of physical interference by larger mussels against small mussels decreases towards the distal positions. The relative effect of interference, however, was constant across upstream-downstream positions, as shown by the linear character of the relationships in Fig. 2.

\section{DISCUSSION}

\section{Interdependence of food and space limitation}

The upstream-downstream pattern of decreasing body mass is consistent with the expected decrease in food from one chamber to the next, and the consequent reductions in growth or body size (Wildish \& Kristmanson 1985, Sebens 1987). The presence of an added component to this pattern is of more relevance to our experiment. This added component resulted from crowding, regardless of the food level in the chambers, except in the most distal positions, where low food level most probably caused emaciation. Therefore food and space limitation were not independent. Rather, they interacted together to produce a response that was asymmetric with respect to mussel size, as small mussels only were affected by crowding. Asymmetry is a common pattern in plant competition (see Weiner 1990). There appears to be a limited number of accounts of asymmetric competition in bivalves. Jarayabhand \& Newkirk (1989) reported a competition-related decrease of individual growth in groups of cultured European oysters Ostrea edulis, but could not determine a precise mechanism of competition. In a natural population of ribbed mussel Geukensia demissa, Bertness \& Grosholz (1985) observed adverse effects of high density to be size-dependent, growth rate being more severely depressed in small individuals. As this effect was correlated with shell deformation, they concluded that crowding was a likely mechanism of competition.

Studies of intraspecific (Bertness \& Grosholz 1985) and interspecific (Harger 1972) interference competition in mussels have implicated the application of external pressure on the shells of the mussels by their competitors, with subsequent impairment of shell opening, as the interference mechanism. Shell opening is a critical factor in controlling mussel pumping rate (Jørgensen et al. 1988), and thus, all other things being equal, food consumption and growth. To model the effect of individual size of competing mussels on the impairment of individual growth, we imagine space-limited mussels of different sizes, oriented parallel to each other, exerting an external pressure on each other's shell. In mussels, as in many bivalves, shell opening is operated passively by the hinge ligament, which operates in opposition to the adductor musculature. We assume that the mussels are relaxed, and that if it were not of interference, they would be pumping at maximum rate, with maximal shell aperture, $r$. Because of space limitation, however, shell opening is impaired by a quantity $\Delta r$ (dimension L, length), which reduces the pumping rate. The change in shell aperture is given by the strain on the ligament $(\varepsilon)$ and the distance between the ligament and the exhalent aperture $(h$, which is assumed to be proportional to shell length). Thus

$$
\Delta r=\varepsilon h
$$

Strain (dimensionless) results from the moment exerted on the hinge ligament of the mussels, which is given by the product of the force exerted on the shells $\left(F\right.$, dimensions $\mathrm{MLT}^{-2}$, where $\mathrm{M}$ and $\mathrm{T}$ are mass and time) and the distance ( $d$, dimension $L)$ between the point where the force is exerted on the shells and the hinge; $d$ is assumed to be proportional to shell length. The elastic modulus of the ligament ( $E$, dimensions $\mathrm{ML}^{-1} \mathrm{~T}^{-2}$ ) and the surface of the ligament ( $S$, dimension $\mathrm{L}^{2}$ ), since the stress is defined as a force per unit area, are also involved in the derivation of the equation relating shell opening to mussel size. Thus

$$
\varepsilon=k_{1} F^{a} d^{b} E^{c} S^{f}
$$

$k_{1}$ being a constant. Since the strain experienced by the ligament is directly proportional to the moment applied, $a$ and $b$ are both equal to 1 . Further, dimensional homogeneity for $M$ requires that $c=-1$. Therefore $f=-3 / 2$ and

$$
\varepsilon=k_{1} F d E^{-1} S^{-3 / 2}
$$

Combining Eqs. (1) and (3), we obtain

$$
\Delta r=k_{1} F d E^{-1} S^{-3 / 2} h
$$

Considering that $d \times l$ and that $h \times l$, and considering that $S^{-3 / 2} \times I^{-3}$ (see Appendix),

$$
\Delta r \propto l \cdot l \cdot l^{-3} \propto l^{-1}
$$

Eq. (5) predicts that the change in shell aperture, and therefore the effect of physical interference, is inversely proportional to shell length. Thus, smaller individuals are disproportionately affected by crowding. 
On the other hand, food consumption $(C)$ is given by the product of filtration (pumping) rate $(V)$ and food concentration (Q), and Winter \& Langton (1976) have observed growth $(G)$ to be proportional to food consumption $\left(G=k_{2} C+b_{1}\right), k_{2}$ and $b_{1}$ being adjusted parameters, which leads to

$$
\Delta V Q \propto \Delta G .
$$

According to Jørgensen et al. (1988), the relationship between shell gape and filtration rate is approximately linear: $\Delta V \propto \Delta r$. Considering Eqs. (5) and (6), we thus write

$$
\Delta r \propto \Delta V \propto \Delta G \propto l^{-1}
$$

The relationship between shell length and body mass can be written as

$$
I \propto m^{\left(\frac{1}{3(1-\alpha)}\right)}
$$

where the parameter $\alpha$ represents the effect of allometry on the shell-length / body-mass relationship. In principle, $0 \leq \alpha<1$, with the lower bound representing isometric growth (Fréchette \& Lefaivre 1990). However, shell-length / body-mass relationships with slopes higher than 3, and as high as 4 , have been observed (Boromthanarat \& Deslous-Paoli 1988), which implies negative values for $\alpha$. From Eqs. (7) and (8), $\Delta G$, the diminution of growth under crowding, is

$$
\Delta G \propto m^{-\left(\frac{1}{3(1-a)}\right)}
$$

Eq. (9) predicts that the change in absolute growth resulting from pressure on the shells decreases with body mass.

The predicted relationship between the change in absolute growth and mussel body size presented in Eq. (9) is dependent on 2 important assumptions. First, a linear relationship between shell gape and pumping rate is assumed. To our knowledge, the only evidence about this relationship is in Jørgensen et al. (1988), who reported an approximately linear relationship between these 2 variables. From their Fig. 4, it appears indeed that for mussels actively regulating valve gape, the relationship is linear. They acknowledged, however, that their data for passive control of valve gape (Fig. 2 in Jørgensen et al. 1988), as few as they may be, suggested a non-linear relationship, with negative curvature. Such an effect could be incorporated in the model by modifying Eq. (7) accordingly. Jørgensen and co-workers, however, provided no quantitative information on the non-linearity of the relationship.

Second, the model assumes that the relationship between food consumption and growth is linear, as observed by Winter \& Langton (1976). Bayne et al. (1989; see also Thompson \& Bayne 1974) studied the response of scope for growth (SFG), a proxy for growth, to food concentration in the laboratory. Their results clearly show that SFG increases non-linearly with food concentration to a horizontal asymptote. We assume that an experiment such as ours, if carried out at or near saturating food levels, would have resulted in smaller and smaller effects of crowding with increasing food concentration, since at asymptotic food concentration, saturation of the feeding apparatus would have been possible despite some impairment of pumping rate. Previous experiments in a location near our site, however, demonstrate that individual growth of mussels is food-limited (Fréchette \& Bourget 1985a, b, Fréchette \& Grant 1991). We thus conclude that the experiment was carried out at non-saturating food concentrations, and that as a first approximation, the assumption of linearity between food concentration and growth is probably realistic. That non-linearity between food concentration and growth in this experiment can be ignored is further supported by the results in Fig. 2, which suggest, judging from the linear character of the relationships, that the effect of interference relative to undisturbed growth was independent of food level. In the present context, therefore, we choose to assume linear relationships, until further data clearly demonstrate their inadequacy, and provide estimates of non-linear effects.

It is unclear why only the small mussels were affected by crowding. A possible reason for the absence of significant effect of interference on large mussels is that according to our interpretation of the data, small mixed mussels failed to consume some amount of available food. It is likely that this food was available for large mussels, and contributed to their food intake, despite some interference by small mussels. The same argument holds for small mixed mussels: it is possible that they profited from extra food availability, which led to some underestimation of the effect of crowding, thereby providing a conservative test of the hypothesis of independence of food and space. Nevertheless, small mussels were affected by crowding.

We have presented above a parsimonious interpretation of our data in terms of competition-induced impairment of shell gape. The response to such conditions, alternatively, may be a change in gill position in such a way that half of the gill is made ineffective for filtration (Dral 1968). This would have resulted in slopes $\approx 0.5$ and $\approx 1$ for small and large mussels, respectively, as observed in Fig. 2 .

In addition to physical interference, the asymmetric character of competition may have been enhanced by a shading process, similar to that observed in bryozoans by Buss (1979), whereby large mussels would 
have protruded farther into the flow than small mussels. If this was coupled with a small-scale depletion of phytoplankton within the chambers, small mussels would have had their water intake height lower in the depleted side of the food gradient, with a consequent reduction of their growth. Notwithstanding the relative importance of pressure on the shells and shading, it is clear that crowding resulted in cooccurrence of interference and food limitations. The issue of identifying the interference mechanism cannot be resolved with the present data. A detailed experimental study of the effect of body size on the outcome of interference competition will be presented elsewhere (Fréchette \& Despland unpubl.).

\section{Self-thinning relationships}

The methodology of using self-thinning relationships to assess whether suspension feeders occurring at high densities are limited by food or space is based on the prediction of self-thinning slopes from densityindependent allometric relationships (Fréchette \& Lefaivre 1990). Food-limited self-thinning slopes (FST) are predicted from the allometric relationship between respiration rate and body mass. Space-limited selfthinning slopes (SST) are predicted from the allometric relationship between shell length and body mass. The prediction of SST may involve 2 other parameters, depending on the situation. One describes the effect of multi-layered packing (Hughes \& Griffiths 1988), and the other accounts for the effect of substratum heterogeneity on the actual surface sampled and inferred population density. According to theoretical expectations, multi-layered packing and substrate heterogeneity both result in increasing the predicted slopes of SST relationships. Both factors act in the same direction, increasing the divergence between predicted FST and SST slopes (Fréchette \& Lefaivre 1990).

As originally stated in Fréchette \& Lefaivre (1990), the method for identifying food or space limitation assumed independence between food and space competition. This was not the case in the present experiment. To account for interdependence of food and space limitation in the self-thinning function, let us consider that in experiments conducted in the natural environment, a decrease in food quantity resulted in a decrease of the intercept of the shell-length/bodymass relationship in mussels, without statistically significant changes in the slope of the relationship (Fréchette \& Bourget 1985a, b), setting aside any effect on growth rate. Mussels had their condition index diminished, independent of their size. In other words, pure food limitation resulted in symmetric competition with respect to size. It is noteworthy that the results of these experiments included the effect of food limitation on growth of both body mass and shell length in an integrated way. They also implicitly took into account confounding factors such as temporal uncoupling between shell growth and body mass growth (Hilbish 1986). From the present experiment, we are led to suggest that interference aggravated food shortage inversely to mussel size. Based on the results of Fréchette \& Bourget $(1985 \mathrm{a}, \mathrm{b})$, we therefore suggest that when crowding interferes with normal feeding, condition index will decrease inversely to mussel size. This will result in tipping the allometric shell-length/ body-mass relationship toward higher values. Consequently, in situations where a size-dependent component to food limitation results from space limitation, the observed self-thinning function would have a steeper slope than expected from pure space limitation. The extent of the inferred increase of the self-thinning slope is difficult to predict at present, as the change in the shell-length/body-mass relationship will be specific to the sites and species considered. However, it is noteworthy that shell-length/body-mass relationships with slopes larger than 3 and as high as 4 , as compared to expected values $\leq 3$ (Schepart7, 1980, Peters 1983), have been observed in mussels cultured in high-density situations (Boromthanarat \& DeslousPaoli 1988) during a period of rapid individual growth apparently coincident with space limitation (Fréchette \& Lefaivre 1990). Such high slopes may have resulted from asymmetric competition, with crowding interfering with normal feeding in small individuals. Far from being an ontogenetic process, this change in the shell-length/body-mass relationship in response to crowding would be a consequence of processes acting at the population and ecosystem levels. Further study would require that individuals grown alone be compared with competing individuals, grown in groups.

Many plant populations exhibit negative relationships between population biomass and density that are characteristic of self-thinning (Weller 1987. Lonsdale 1990). Explanations of the variability in the slope of thinning relationships in plants point to ontogenetic and phylogenetic factors (Weller 1987, Norberg 1988, Lonsdale 1990). Such patterns have also been reported in benthic animal populations (Levitan 1989, Fréchette \& Lefaivre 1990 and references therein), as well as in whole intertidal communities (Marquet et al. 1990). Our results show that in addition to ontogenetic and phylogenetic factors, variability in predicted selfthinning lines in sessile suspension-feeding animals is to be expected from the nature of the interactions between organisms. We suggest that future work on density-dependent growth and survival in bivalves address the effect of different competition mechanisms on the shell-length/body-mass relationship, as it plays a central role in the prediction of self-thinning slopes. 


\section{APPENDIX}

The relationship between ligament surface and shell length was examined by cutting a longitudinal section across the ligament of mussels of different sizes. The surface of the ligament was digitized using a BIOSONICS Optical Pattern Recognition System. The relationship between the surface of the whole ligament $\left(S, \mathrm{~cm}^{2}\right)$ and shell length $\left(I_{1} \mathrm{~cm}\right)$ is given by $\log S=3.94+1.84 \log l\left(\mathrm{r}^{2}=0.73, \mathrm{n}=33, \mathrm{p}<0.01\right)$. Since the slope is not significantly different from $2(T=0.39,13 \mathrm{df}, \mathrm{p}>0.5)$, we approximate $S$ as being proportional to $l^{2}$ Thus, $S^{-3 / 2} \times 1^{-3}$

Acknowledgements. A.E.A. was supported by the Natural Science and Engineering Research Council of Canada. We thank D. Baudinet, J. Grant and D. Lefaivre for helpful discussions and comments on the manuscript. Three anonymous referees critically reviewed the manuscript, and we are grateful for their contribution

\section{LITERATURE CITED}

Anholt, B. R. (1990). An experimental separation of interference and exploitative competition in a larval damselfly. Ecology 71: 1483-1490

Bayne, B. L., Hawkins, A. J. S., Navarro, E., Iglesias, I. P. (1989). Effects of seston concentration on feeding, digestion and growth in the mussel Mytilus edulis. Mar. Ecol. Prog. Ser. 55: 47-54

Beddington, J. R. (1975). Mutual interference between parasites or predators and its effect on searching efficiency. J. Anim. Ecol. 44: 331-340

Bertness, M. D., Grosholz, E. (1985). Population dynamics of the ribbed mussel, Geukensia demissa: the costs and benefits of an aggregated distribution. Oecologia 67: 192-204

Boromthanarat, S., Deslous-Paoli, J.-M. (1988). Production of Mytilus edulis reared on bouchots in the bay of MarennesOléron: comparison between two methods of culture. Aquaculture 72: 255-263

Buss, L. W. (1979). Bryozoan overgrowth interactions - the interdependence of competition for space and food. Nature, Lond. 281: 475-477

Clarke, M. R. B. (1980). The reduced major axis of a bivariate sample. Biometrika 67: 441-446

Dral, A. D. G. (1968). On the feeding of mussels (Mytilus edulis L.) in concentrated food suspensions. Neth. J. mar Res. 18: $440-441$

Fréchette, M., Bourget, E. (1985a). Energy flow between the pelagic and benthic zones: factors controlling particulate organic matter available to an intertidal mussel bed. Can. J. Fish. Aquat. Sci. 42: 1158-1165

Fréchette, M., Bourget, E. (1985b). Food-limited growth of Mytilus edulis in relation to the benthic boundary layer Can. J. Fish. Aquat. Sci. 42: 1166-1170

Fréchette, M., Butman, C. A., Geyer, W. R. (1989). The importance of boundary-layer flows in supplying phytoplankton to the benthic suspension feeder, Mytilus edulis L. Limnol. Oceanogr. 34: 19-36

Fréchette, M., Grant, J. (1991). An in situ estimation of the effect of wind-driven resuspension on the growth of the mussel Mytilus edulis L. J. exp. mar. Biol. Ecol. 148: $201-213$

Fréchette, M., Lefaivre, D. (1990). Discriminating between food and space limitation in benthic suspension feeders using self-thinning relationships. Mar. Ecol. Prog. Ser. 65: $15-23$

Harger, J. R. (1972). Competitive co-existence: maintenance of interacting associations of the sea mussels Mytilus edulis and Mytilus californianus. Veliger 14:387-410
Hilbish, T J. (1986). Growth trajectories of shell and soft tissue in bivalves: seasonal variation in Mytilus edulis $\mathrm{L}$ J. exp. mar. Biol. Ecol. 96: 103-113

Hughes, R. N., Griffiths, C. L. (1988). Self-thinning in barnacles and mussels. Am. Nat. 132: 484-491

Jarayabhand, P., Newkirk, G. F. (1989). Effects of intraspecific competition on growth of the European oyster, Ostrea edulis Linnaeus, 1750. J. Shellfish Res. 8: 359-365

Jensen, A. L. (1987). Simple models for exploitative and interference competition. Ecol. Modelling 35: 113-121

Jørgensen, C. B., Larsen, P. S., Møhlenberg, F., Riisgård, H. U. (1988). The mussel pump: properties and modelling. Mar Ecol. Prog. Ser. 45: 205-216

Levitan, D. R. (1989). Density-dependent size regulation in Diadema antillarum: effects on fecundity and survivorship. Ecology 70: 1414-1424

Lonsdale, W. M. (1990). The self-thinning rule: dead or alive? Ecology 71: 1373-1388

MacIsaac, H. J., Gilbert, J. J. (1991). Discriminating between exploitative and interference competition between Cladocera and Keratella cochlearis. Ecology 72: 924-937

Marçuet, P. A., Navarrete, S. A., Castilla, J. C. (1990). Scaling population density to body size in rocky intertidal communities. Science 250: 1125-1127

Myers, P. E. (1990). Space versus other limiting resources for a colonial tunicate, Botrylloides leachii (Savigny), on fouling plates. J. exp. mar. Biol. Ecol. 141: 47-52

Norberg, $\AA$. (1988). Self-thinning of plant populations dictated by packing density and individual growth geometry and relationships between animal population density and body mass governed by metabolic rate. In: Ebenman, B., Persson, L. (eds.) Size-structured populations. Ecology and evolution. Springer-Verlag, Berlin, p. 259-279

Okamura, B. (1986). Group living and the effect of spatial position in aggregations of Mytilus edulis. Oecologia 69: 341-347

Peters, R. H. (1983). The ecological implications of body size. Cambridge University Press, Cambridge

Peterson, C. H. (1982). The importance of predation and intraand interspecific competition in the population biology of two infaunal suspension-feeding bivalves, Protothaca staminea and Chione undatella. Ecol. Monogr. 52: $437-475$

Peterson, C. H., Andre, S. V. (1980). An experimental analysis of inter-specific competition among marine filter feeders in a soft-sediment environment. Ecology 61: 129-139

Schepartz, B. (1980). Dimensional analysis in the biomedical sciences. C. C. Thomas, Springfield, Illinois

Schoener, T W. (1973). Population growth regulated by intraspecific competition for energy or time: some simple representations. Theor. Popul. Biol. 4: 56-84

Sebens, K. P. (1987). The ecology of indeterminate growth in animals. Ann. Rev. Ecol. Syst. 18: 371-407

Thompson, R. J. (1984). The reproductive cycle and physiological ecology of the mussel Mytilus edulis in a subarctic non-estuarine environment. Mar. Biol. 79: 277-288

Thompson, R. J., Bayne, B. L. (1974). Some relationships be- 
tween growth, metabolism and food in the mussel Mytilus edulis. Mar. Biol. 27: 317-326

Weiner, J. (1990). Asymmetric competition in plant populations. Trends Ecol. Evol. 5: 360-364

Weller, D. E. (1987). Self-thinning exponent correlated with allometric measures of plant geometry. Ecology 68: 813-821

Weller, D. E. (1990). Will the real self-thinning rule please stand up? A reply to Osawa and Sugita. Ecology 71 $1204-1207$

Wildish, D. J., Kristmanson, D. D. (1985). Control of suspension feeding bivalve production by current speed.

This axticle was submitted to the editor
Helgoländer Meeresunters. 39: 237-243

Winter, J. E., Langton, R. W. (1976). Feeding experiments with Mytilus edulis L. at small laboratory scale. I. The influence of the total amount of food ingested and food concentration on growth. In: Persoone, G., Jaspers, E. (eds.) Proc. 10th European Symposium on Marine Biology, Ostend, Belgium. Universa Press, Wetteren, p. 565-581

Yoda, K., Kira, T., Ogawa, H., Hozumi, K. (1963). Selfthinning in overcrowded pure strands under cultivated and natural conditions (Intraspecific competition among higher plants XI). J. Biol. Osaka City Univ. 14: 107-129

Manuscript first received: September 23, 1991 Revised version accepted: April 15, 1992 